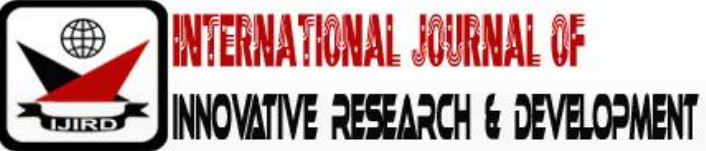

ISSN 2278 - 0211 (Online)

\section{Awareness of Routine Breast Screening and Breast Cancer in Jos North Central Nigeria}

\begin{tabular}{|c|}
\hline Gabkw et AE \\
Lecturer, Department of Radiology, Jos University Teaching Hospital, Nigeria \\
Igoh EO \\
Lecturer, Department of Radiology, Jos University Teaching Hospital, Nigeria \\
Gwom PM \\
Taiwo YF \\
Tonsultant Radiologist, Department of Radiology Federal Medical Center Keffi, Nigeria \\
Lecturer, Department of Radiology, Jos University Teaching Hospital, Nigeria \\
Salaam AJ \\
Senior Lecturer, Department of Radiology, Jos University Teaching Hospital, Nigeria \\
Danjem SM \\
Senior Lecturer, Department of Radiology, Jos University Teaching Hospital, Nigeria \\
\hline
\end{tabular}

\begin{abstract}
:
Background: Despite recent studies showing great improvement in the level of awareness of breast cancer, late presentation by sufferers of this disease still persist.

Objective: To determine the level of awareness of routine breast cancer screening modalities and breast cancer amongst women in North Central Nigeria.

Methods: This is a cross sectional study conducted using randomly selected consenting women to determine the level of awareness of routine breast cancer screening and breast cancer.

Results: Three hundred and ninety-eight women participated in the study with mean age of $41.8 \pm 10.5$. Majority are married (51.3\%) and had attained tertiary education (66.3\%). About ninety eight percent $(98.5 \%)$ of the women are aware of breast cancer and the main sources of information includes health personnel (41.0\%) and social media (28.1\%). On the overall, knowledge of risk factors and symptoms of breast cancer was poor. Statistically significant relationship between knowledge of risk factors with age and educational level was noted.

Conclusion: Study showed high level of awareness of breast cancer with a rather poor knowledge of risk factors and symptoms of the disease
\end{abstract}

Keywords: Breast cancer, screening, awareness, knowledge

\section{Introduction}

The incidence of cancer is increasing globally with a greater burden expected to be borne by poor and middle income countries by 2030 where the will and resources to tackle the situation are absent ${ }^{1}$.In a report published by JedyAgba E et al in 2012 from population-based cancer registries in the Southwest and North central region of Nigeria shows that the most common male and female cancers in Nigeria are cancer of the prostate and cancer of the breast respectively ${ }^{2}$. The peak incidence of breast cancer in Nigerian women is about a decade earlier than in Caucasians with about $57 \%$ of breast cancer cases in Nigeria occurring in women under 50 years of age ${ }^{3}$.In Nigeria and most sub-Saharan African countries, breast cancer patients generally tend to present at a younger age when compared to Caucasians and most of the presentations are in the late stages of the disease when the prognosis is really poor 4,5 .

The lower proportion of mortality recorded in the developed nations is a result of better awareness of the disease, more organized screening programs for early detection and availability of an effective treatment. Studies in Nigeria show a high level of breast cancer awareness as a fatal disease that needs early detection for a better outcome. However, the high level of awareness does not translate to a higher rate of screening practice 6,7. Globally, it is an agreed fact that early detection of breast cancer improves the survival rate, hence screening of otherwise healthy patients is advocated especially those with a family history of breast cancer 8,9 .

Screening programs exist in most western nations were early breast cancer detection screening techniques like Breast Self-Examination (BSE), Clinical Breast Examination (CBE) and mammogram are being advocated. Although, in some countries, it has become a point of criticism in recent years owing to the facts that it has led to an increase in healthcare cost and detection of otherwise clinically insignificant breast lesions. The American Cancer Society (ACS) 
recommends mammogram and CBE every year for women aged 40 years and monthly BSE as an option for women between 20-40years ${ }^{10}$.

Many studies on breast cancer awareness and knowledge of symptoms and screening methods have been undertaken in the southern part of Nigeria3,4,5,6,7. The need to know the level of awareness of this disease in the North Central region of Nigeria vis a vis the increasing number of young women who are diagnosed with breast cancer in this region necessitated this study.

\section{Materials and Methods}

This was a cross sectional community base study conducted among women in both formal and informal settings in Jos North Central Nigeria to determine level of awareness of routine breast cancer screening and breast cancer conducted from February 2019 to September 2019.

Women between the age of 30 and above who consented were recruited while women who were less than 30 years or declined to participate were excluded. A systemic random sampling technique was used to select participants aged 30years and above.

A total of 398 participants were recruited and a structured questionnaire was self-administered for literate participants and trained interviewer used for participants who don't understand English. The questionnaire has four sections viz; (i) socio-demographics of participant (ii) awareness of breast cancer (iii) knowledge of risk factors and symptoms of breast cancer (iv) knowledge of screening methods. Informed consent was obtained from the participants before the administration of the questionnaires.

The data collected was collated and analyzed using the IBM SPSS STATISTICS VERSION 22.0 and EXCEL OFFICE 2013 was used to plot the charts.

Statistical significance was tested using Chi-square distribution (for test of difference in proportions). A p-value less than or equal to 0.05 was considered statistically significance.

\section{Results}

\subsection{Socio-Demographic Characteristics of Participants}

Three hundred and ninety-eight women participated in the study. The mean age of the women was $41.8 \pm 10.5$ with a range of 30-79 years. The age distribution shows that more than a third of the participants were in the age group 30 -35years accounting for $40.5 \%$.

About two third of participants (66.3\%) had attained tertiary level of education while $7.5 \%$ had no formal education.

\subsubsection{Awareness of Breast Cancer}

Majority of the participants (98.5\%) were aware of Breast cancer and attributed their source of information to Health personnel (41.0\%) followed by Social media (28.1\%) and Friend (25.1\%). A good number of the participants had multiple source of information regarding breast cancer (Table 1).

\subsubsection{Knowledge of Risk Factors for Breast Cancer}

More than half of the participants (58.8\%) opined that being a woman is a risk factor for breast cancer. Only a few (3.0\%) opined that late menopause is a risk factor. Many of the participants are aware of multiple risk factors linked to breast cancer (Table 2).

On the overall, majority of the participants (85.9\%) had poor knowledge, 50(12.6\%) had good knowledge and $6(1.5 \%)$ had no knowledge at all on risk of breast cancer. Majority of the participants (89.9\%) had awareness on breast cancer screening.

\subsubsection{Knowledge of Breast Cancer Screening Methods}

Most of the participants were aware of more than one Breast Cancer Screening modality. Three hundred and ten participants (77.9\%) were aware of Self-breast examination as a modality. Others 242(60.8\%) and 265(66.6\%) are aware that Breast ultrasound scan and Mammography are a screen modalities (Table 3).

Knowledge of Sign and Symptoms of Breast Cancer

The study revealed that 158(39.7\%) participants identified painless lump as a symptom of Breast Cancer and a greater proportion 232(58.3\%) identified painful lump while (25.9\%) and (44.5\%) think Ulcer/ Sores on the breast and Bloody nipples discharge are symptoms respectively. Lump in the armpit/ axilla account for (39.9\%) of the respondents, Change in breast skin color (35.4\%) and Nipple pulling/ retraction (32.4\%). ( Table 4).

Relationship between Demographic characteristics of participants and Knowledge of Breast Cancer

The study showed a significant relationship between knowledge of risk factors and age $(p=0.002)$.

There was no statistical relationship between marital status and knowledge of risk factors $(p=0.204)$. This suggests that marital status is not a determinant of the knowledge of breast mass/ cancer.

There was a statistically significant relationship between educational level (qualification) and knowledge of the risk factor of breast mass/ cancer $(\mathrm{p}=0.000)$. $=0.011)$

The study also revealed that Occupation was a determinant for knowledge of risk factors of breast mass/ cancer ( $p$

Parity was not a significant determinant of knowledge on risk factors of breast mass/ cancer ( $p=0.273$ ). (Table 5). Relationship between Demographic data and Knowledge of Breast Cancer Screening Modalities 
The study showed a significant relationship between age and knowledge on the Breast Cancer Screening Modalities $(p=0.048)$. Majority of the participants who had good knowledge were between the ages of 30-35 years (36.7\%) and 36-39 years respectively (15.5\%). There was no statistical relationship between marital status and knowledge of BCS modalities $(\mathrm{p}=0.052)$.

The study shows a significant relationship between educational level and knowledge of BCS modalities $(p=$ 0.024). Participants with Tertiary educational qualification dominated the study group.

Most of the participants with good knowledge of BCS modalities were Civil servants. There was a significant relationship between occupation and knowledge of BCS modalities ( $p=0.025)$.

Knowledge of the Breast Cancer Screening modalities was found to be statistically significant with Parity $(p=$ 0.018). (Table 7). Relationship between Demographic and knowledge on Signs and Symptoms

The study showed a significant relationship between age and Knowledge of Signs and Symptoms of Breast Cancer $(p=0.000)$. Majority of the participants who had good knowledge were between the ages of 30-35 years (44.1\%) and 46-49 years respectively (12.6\%). There was no statistically significant relationship between marital status and Knowledge on Signs and Symptoms of Breast Cancer $(p=0.130)$.

The study shows a significant relationship between educational level and Knowledge of Signs and Symptoms of Breast Cancer $(\mathrm{p}=0.000)$. Participants with Tertiary educational qualification dominated the study group.

Most of the participants with good knowledge of Signs and Symptoms of Breast Cancer were Civil servants. There was no significant relationship between occupation and Knowledge on Signs and Symptoms of Breast Cancer $(p=0.545)$.

Knowledge of Signs and Symptoms of Breast Cancer was found to be statistically significant with Parity ( $p=0.001)$. (Table 6)

\section{Discussion}

Breast cancer has remained the foremost malignancy in women globally and a leading cause of death 4,8 .

In sub-Saharan Africa and Nigeria in particular, studies have shown that the prevalence of breast cancer could be higher due to lack of cancer registries in these countries and deaths from this disease are on the increase and yet many cases remain unreported 9 .

In Nigeria, despite growing awareness regarding the disease, the level of breast cancer screening has remained very low with the rate of late presentation of the disease persistently high 7 . The reasons attributed to the late presentation differ globally. In a study done among Pakistani women by Khan MA et al 2015 attributed the reason for late presentation to painless breast lump, lack of resources and preference for alternative care, while in Brazil, frequent barriers to the early presentation were hospital-related11,12. In a similar study done in Kenya by Otieno ES e al 2010; Fear of the unknown, painless lump and missed diagnosis in the hospitals are some of the reasons associated with late presentation ${ }^{13 .}$

Breast screening programs in Sub-Saharan Africa are largely unstructured. In Nigeria for example, only Lagos State, the commercial capital and Abuja the administrative capital city can boast of organized structured breast cancer screening program which is basically managed by private organization with little or no Government involvement. In these mentioned areas, public awareness campaigns are used to invite women to participate in free screening programs. Despite this awareness program, recent data showed that the majority of eligible women have not participated regularly 14.

In the United State of America and Canada, the successes recorded in breast cancer screening are attributed to the use of both public awareness campaign and the use of print and social media ${ }^{14}$.

In this study, there was a high level of breast cancer awareness (98.5\%) amongst the participants and a good percentage of the participants attributed their knowledge to information gotten from Health personnel and media (TV/ Radio). This is in agreement with similar findings reported in Southwest and Southeast of Nigeria respectively 6,15. These findings have shown the importance of health personnel and media in proper dissemination of information and the need for more advocacies in these regards. A majority of the participants (58.8\%) opined that being a woman is the number one risk factor for breast cancer. Family history of breast cancer and a previous history of breast mass in an individual account for $43 \%$ and $42.7 \%$ respectively. Only 3\% ascribed late menopause as a risk factor. These findings are not in agreement with Alcohol intake and oral contraceptive use being key factors for breast cancer risk in a similar study among secondary school teachers in South East Nigeria. Cigarette smoking and family history of breast cancer was ascribed as the leading risk factor in Northwest of Nigeria 15,17 .

Overall, our findings show 1.5\% of respondents have no knowledge of breast cancer, $12.6 \%$ had good knowledge while a majority $85 \%$ had poor knowledge of the risk factors.

A good number of the participants (77.9\%) singled out Breast Self-Examination (BSE) as a method of breast cancer screening while $66.6 \%$ and $60.3 \%$ opined that mammography and breast ultrasound scan are modalities for screening. A majority of the respondents know at least two screening methods. In general, our study showed that $52 \%$ of the participants have good knowledge of methods used in breast cancer screening. These findings are in tandem with a moderate proportion (43-56\%) of women with good knowledge of breast cancer screening strategies as reported in a similar study done in Kaduna Northwestern Nigeria by Azubuike et al (2016). On the contrary, Heidari et al (2006) reported a lower percentage of women $(21.6 \%)$ in a study done in Iran 17,18 .

In a study done by Salam HE et al in Iran 77\% of participants have a good idea about BSE as a screening modality, a good number of them know how to go it while only $24 \%$ actually practice it.

In summary, this study showed that age, a higher level of education, occupation, and parity of the respondents have a significant statistical relationship with the level of knowledge of breast cancer screening modalities. Findings from our study showed $58.3 \%$ of the respondents acknowledged painful breast lump as the leading symptom of breast cancer 
while $44.5 \%$ and $39.9 \%$ indicated that bloody nipple discharge and lump in the axilla are symptoms. A good number of the respondents indicated more than one symptom in the study.

A similar study undertaken in Northwest Nigeria reported pain in the breast as the leading symptom $57.4 \%$, followed by nipple discharge (46.7\%) and a painless lump was acknowledged by $45.2 \%$ of the respondents. These findings are similar to ours, but are however in contrast with a study done by Osiwe OC et al in 2008 in Benin City South Nigeria where painless lump accounted for $81.8 \%$ of the key symptoms indicated and a much lower percentage quoted in a study by Pharm CT et al among Vietnamese Women $20,21,22$.

According to the American Cancer Society publication on Breast cancer signs and symptoms (2019), the most common symptom of breast cancer is a new painless hard lump or mass that has irregular edges. The low percentage of participants $(39.7 \%)$ ascribing painless lump as a symptom could be attributed to cultural practices in our environment.

Early detection of breast cancer is key in its treatment and prognosis and therefore, knowledge of painless breast lump as the commonest symptom of breast cancer is key in minimizing mortality and morbidity associated with the disease in a low resource environment like ours.

\section{Conclusion}

This study showed a high level of awareness of breast cancer and screening methods with a rather poor knowledge of risk factors, signs and symptoms of the disease among the respondents.

\section{Recommendations}

- $\quad$ Health education on breast cancer should focus on creating awareness about common risk factors and symptoms of the disease.

- $\quad$ Emphasis should be on young people in secondary schools and higher institutions of learning.

- $\quad$ A National Breast Cancer screening and treatment program should be instituted

- $\quad$ More Hospitals should be equipped with the necessary screening modalities.

\section{References}

i. Boyle P, Howel A. The Globalization of Breast Cancer. Breast Cancer Research (2010).12 (4) S7

ii. Jedy-Agba E, Maria PC, Olufemi O, Emmanuel O et al. Cancer incidence in Nigeria. A report from population-based cancer registries. Cancer Epidemiology (2012) .36 (5):271-278.

iii. Okobia MN, Bunker CH, Okonofua FE, Osime U. Knowledge, attitude and practice of Nigerian women towards breast cancer: a cross-sectional study. World Journal of Surgical Oncology (2006). 4:11

iv. Adebamowo CA, Ajayi OO. Breast Cancer in Nigeria. West African Journal of Medicine (2000).19:179-191

v. Obajimi MO, Ajayi IO, Oluwasola AO, Adedokun BO et al. Level of awareness of mammography among women attending outpatient clinics in a teaching hospital in Ibadan, South-West Nigeria. BMC Public Health. (2013). 13(40):1-7.

vi. TO Bello, A.I Olugbenga, AS Oguntola, ML Adeoti. Knowledge and Practice of Breast cancer screening Among Female Nurses and Lay women in Osogbo, Nigeria. West African Journal of Medicine (2011).30 (4):296-300.

vii. Agodirin SO, Akande JH, Olatoke AS, Rahman AGaniyu1, Oguntola A Level of Awareness and Knowledge of Breast Cancer in Nigeria. A Systematic Review. Ethiopian Journal of Health Science (2017).27 (2):163-174.

viii. Parkin DM, Bray F, Ferlay J, Pisani P. Global cancer statistics. CA Cancer Journal for Clinicians (2005). 55:74-108.

ix. Samuel NC, Kenneth NN, Joyce MT Breast Cancer among women in Sub-Saharan Africa: Prevalence and situational Analysis. Southern African Journal of Gynecological Oncology (2017). 9(2).

x. American cancer society. Breast cancer facts and figures 2011-2012.Atlanta, GA

xi. Khan MA, Hanif S, Igbal S, Shahzad MF, Shafique S Presentation delay in breast cancer patients and its association with sociodemographic factors in North Pakistan. Chinese Journal of Cancer Research (2015).27 (3):288-293.

xii. Goncalves LT, G Almeida A, Guimaraes M, Gois C Barriers in Health Care to Breast cancer; Perception of Women.Rev Esv Enferm (2014).48 (3):394-400.

xiii. Otieno ES, Micheni JN, Kimende SK, Mutal KK Delayed presentation of breast cancer patients/ East African Medical Journal (2010). 87(4):147-150.

xiv. Lawal O. Murphy FJ,Hogg P,Irurhe N,Nightingale J Mammography screening in Nigeria. A critical comparison to other countries. Radiography (2015). 21(4):348-351

xv. Chinomnso CN, Uche M, Prince CE, Gift OE .Breast Cancer Awareness, Knowledge and Screening uptake among Female secondary school Teachers in Owerri, Nigeria. Journal of Cancer and Tumor International (2018).7 (4):113.

xvi. Samuel OA Breast cancer risk factors and sign: How much do Nigerian women know? International Journal of Advanced Medical and Health Research (2019) .4 (1):40-43.

xvii. Azubuike SO, Celestina UO Breast cancer: The perspective of northern Nigerian women. International Journal of Preventive Medicine (2015).. 6: 130

xviii. Z Z Heidari, HR Mahmoudzaded-Sagheb, N Sakhavar. Breast Cancer Screening Knowledge and Practice among women in Southeast of Iran. Acta Medica Iranica, (2008). 46 (4):321-328.

xix. Salam HE, Ali MS, Raghed HM Knowledge and practice of breast self-examination among sample of women in Shatra.Alexandra Journal of Medicine (2018). 54:315-317

xx. Azubuike SO, Okwuokei SO Knowledge, Attitude and Practice of Women towards Breast Cancer in Benin City Nigeria. Annal of Medical and health sciences research (2013).3: 155-160 
xxi. Osime OC, Okojie O, Aigbekaen ET, Aigbekaen IJ Knowledge attitude and Practice about breast cancer among civil servants in Benin City, Nigeria. Annal of African Medicine. (2008). 7(4):192-197.

xxii. Pham CT, McPhee SJ). Knowledge, attitudes, and practices of breast and cervical cancer screening among Vietnamese women. Journal of Cancer Education (1992) .7: 305-10.

\section{Appendix}

\begin{tabular}{|c|c|c|}
\hline Sources & F & $\mathbf{\%}$ \\
\hline From friend & 100 & 25.1 \\
\hline TV/ Radio & 91 & 22.9 \\
\hline Social media & 112 & 28.1 \\
\hline Health personnel & 163 & 41.0 \\
\hline Newspaper/ Magazine & 24 & 6.0 \\
\hline Others & 18 & 4.5 \\
\hline
\end{tabular}

Table 1: Sources of Awareness of Breast Cancer $(\mathrm{N}=398)$

\begin{tabular}{|c|c|c|}
\hline Risk Factors for Breast Mass/ Cancer & f & $\mathbf{\%}$ \\
\hline Being a woman & 234 & 58.8 \\
\hline Increasing age & 136 & 34.2 \\
\hline Genetic mutation & 116 & 29.1 \\
\hline Smoking & 104 & 26.1 \\
\hline Oral contraceptives & 36 & 9.0 \\
\hline Fatty diet & 117 & 29.4 \\
\hline Early menstruation & 31 & 7.8 \\
\hline Late menopause & 12 & 3.0 \\
\hline Having dense breast & 124 & 31.2 \\
\hline Personal history of breast mass & 170 & 42.7 \\
\hline Family history of breast cancer & 171 & 43.0 \\
\hline Previous history of radiation treatment & 157 & 39.4 \\
\hline Overweight/ Obesity & 37 & 9.3 \\
\hline Hormonal therapy & 120 & 30.2 \\
\hline Alcohol consumption & 63 & 15.8 \\
\hline
\end{tabular}

Table 2: Knowledge on Risk Factors of Breast Cancer $(\mathrm{N}=398)$

\begin{tabular}{|c|c|c|}
\hline BCS modalities & Frequency & Percent (\%) \\
\hline Self-breast examination & 310 & 77.9 \\
\hline Breast ultrasound scan & 242 & 60.8 \\
\hline Mammography & 265 & 66.6 \\
\hline Digital Breast Tomosynthesis & 8 & 2.0 \\
\hline Breast Ductography & 28 & 7.0 \\
\hline Breast MRI scan & 110 & 27.6 \\
\hline
\end{tabular}

Table 3: Knowledge on Breast Cancer Screening Methods ( $\mathrm{N}=398$ )

\begin{tabular}{|c|c|c|}
\hline Signs & frequency & Percent (\%) \\
\hline Painless lump & 158 & 39.7 \\
\hline Painful lump & 232 & 58.3 \\
\hline Ulcer/ Sores on the breast & 103 & 25.9 \\
\hline Bloody nipples discharge & 177 & 44.5 \\
\hline Lump in the armpit/ axilla & 159 & 39.9 \\
\hline Change in breast skin color & 141 & 35.4 \\
\hline Nipple pulling / retraction & 129 & 32.4 \\
\hline
\end{tabular}

Table 4: Knowledge of Sign and Symptoms of Breast Cancer $(\mathrm{N}=398)$ 


\begin{tabular}{|c|c|c|c|c|c|c|}
\hline \multicolumn{2}{|c|}{ K'; $[\mathbf{P}$} & \multicolumn{2}{|c|}{ Knowledge of Risk Factors for Breast Mass/ Cancer } & \multirow{2}{*}{ Chi-square } & \multirow{2}{*}{ P-value } \\
& $\begin{array}{c}\text { No } \\
\text { knowledge }\end{array}$ & $\begin{array}{c}\text { Poor } \\
\text { knowledge }\end{array}$ & $\begin{array}{c}\text { Good } \\
\text { knowledge }\end{array}$ & Total & & \\
\hline Age (years) & $0(0.0)$ & $189(55.3)$ & $30(60.0)$ & $219(55.1)$ & 18.865 & 0.016 \\
\hline $30-39$ & $2(33.3)$ & $75(21.9)$ & $12(24.0)$ & $89(22.4)$ & & \\
\hline $40-49$ & $2(33.3)$ & $52(15.2)$ & $4(8.0)$ & $58(14.6)$ & & \\
\hline $50-59$ & $2(33.3)$ & $20(5.9)$ & $4(8.0)$ & $26(6.5)$ & & \\
\hline $60-69$ & $0(0.0)$ & $6(1.8)$ & $0(0.0)$ & $6(1.5)$ & & \\
\hline $70-79$ & & & & & & \\
\hline Educational level & $0(0.0)$ & $26(7.6)$ & $4(8.0)$ & $30(7.5)$ & 50.908 & 0.000 \\
\hline None & $4(66.7)$ & $16(4.7)$ & $0(0.0)$ & $20(5.0)$ & & \\
\hline Primary & $0(0.0)$ & $72(21.1)$ & $12(24.0)$ & $84(21.1)$ & & \\
\hline Secondary & $2(33.3)$ & $228(66.7)$ & $34(68.0)$ & $264(66.3)$ & & \\
\hline Tertiary & & & & & & \\
\hline Occupation & $2(33.3)$ & $55(16.1)$ & $8(16.0)$ & $65(16.3)$ & 19.720 & 0.011 \\
\hline Housewife & $0(0.0)$ & $86(25.1)$ & $22(44.0)$ & $108(27.1)$ & & \\
\hline Business & $2(33.3)$ & $122(35.7)$ & $6(12.0)$ & $130(32.7)$ & & \\
\hline Civil servant & $0(0.0)$ & $39(11.4)$ & $8(16.0)$ & $47(11.8)$ & & \\
\hline Public servant & $2(33.3)$ & $40(11.7)$ & $6(12.0)$ & $48(12.1)$ & & \\
\hline Others & &
\end{tabular}

Table 5: Relationship between Demographic and Knowledge of Breast Cancer $(\mathrm{N}=398)$

\begin{tabular}{|c|c|c|c|c|c|c|}
\hline Variables & \multicolumn{4}{|c|}{ Knowledge On Breast Cancer Screening Modalities } & \multirow{2}{*}{$\begin{array}{c}\text { Chi- } \\
\text { square }\end{array}$} & \multirow{2}{*}{$\begin{array}{c}\text { P- } \\
\text { value }\end{array}$} \\
\hline Age (years) & $\begin{array}{c}\text { No } \\
\text { knowledge }\end{array}$ & $\begin{array}{c}\text { Poor } \\
\text { knowledge }\end{array}$ & $\begin{array}{c}\text { Good } \\
\text { knowledge }\end{array}$ & Total & & \\
\hline $30-39$ & $10(50.0)$ & $101(59.0)$ & $108(52.2)$ & $219(55.1)$ & 19.743 & 0.011 \\
\hline $40-49$ & $2(10.0)$ & $42(24.6)$ & $45(21.8)$ & $89(22.4)$ & & \\
\hline $50-59$ & $6(30.0)$ & $24(14.0)$ & $28(13.5)$ & $58(14.6)$ & & \\
\hline $60-69$ & $2(10.0)$ & $4(2.3)$ & $20(9.7)$ & $26(6.5)$ & & \\
\hline $70-79$ & $0(0.0)$ & $0(0.0)$ & $6(2.9)$ & $6(1.5)$ & & \\
\hline \multicolumn{7}{|l|}{ Marital status } \\
\hline Married & $10(50.0)$ & 93(54.4) & 101(48.8) & $204(51.3)$ & 9.386 & 0.052 \\
\hline Single & $8(40.0)$ & $66(38.6)$ & $70(33.8)$ & $144(36.2)$ & & \\
\hline Divorced/Widowed & $2(10.0)$ & $12(7.0)$ & $36(17.4)$ & $50(12.6)$ & & \\
\hline \multicolumn{7}{|l|}{ Educational level } \\
\hline None & $2(10.0)$ & $8(4.7)$ & $20(9.7)$ & $30(7.5)$ & 14.596 & 0.024 \\
\hline Primary & $4(20.0)$ & $8(4.7)$ & $8(3.9)$ & $20(5.0)$ & & \\
\hline Secondary & $2(10.0)$ & $36(21.1)$ & $46(22.2)$ & $84(21.1)$ & & \\
\hline Tertiary & $12(60.0)$ & $119(69.6)$ & $133(64.3)$ & $264(66.3)$ & & \\
\hline \multicolumn{7}{|l|}{ Occupation } \\
\hline Housewife & $6(30.0)$ & $21(12.3)$ & $38(18.4)$ & $65(16.3)$ & 17.578 & 0.025 \\
\hline Business & $4(20.0)$ & $42(24.6)$ & $62(30.0)$ & $108(27.1)$ & & \\
\hline Civil servant & $6(30.0)$ & $54(31.6)$ & $70(33.8)$ & $130(32.7)$ & & \\
\hline Public servant & $2(10.0)$ & $22(12.9)$ & $23(11.1)$ & $47(11.8)$ & & \\
\hline Others & $2(10.0)$ & $32(18.7)$ & $14(6.8)$ & $48(12.1)$ & & \\
\hline \multicolumn{7}{|l|}{ Parity } \\
\hline None & $6(30.0)$ & 73(42.7) & $68(32.9)$ & $147(36.9)$ & 18.455 & 0.018 \\
\hline $1-3$ & $6(30.0)$ & $52(30.4)$ & $73(35.3)$ & 131(32.9) & & \\
\hline $4-6$ & $4(20.0)$ & $34(19.9)$ & $38(18.4)$ & $76(19.1)$ & & \\
\hline $7-9$ & $4(20.0)$ & $12(7.0)$ & $16(7.7)$ & $32(8.0)$ & & \\
\hline $10+$ & $0(0.0)$ & $0(0.0)$ & $12(5.8)$ & $12(3.0)$ & & \\
\hline
\end{tabular}

Table 6: Relationship between Demographic and Knowledge of Screening Modalities ( $\mathrm{N}=398$ ) 